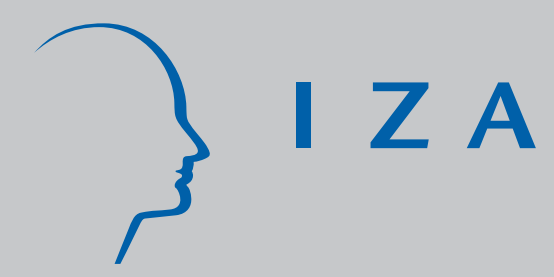

IZA DP No. 1758

Incentives, Decision Frames, and Motivation Crowding Out - An Experimental Investigation

Bernd Irlenbusch

Dirk Sliwka

September 2005 


\title{
Incentives, Decision Frames, and Motivation Crowding Out - An Experimental Investigation
}

\author{
Bernd Irlenbusch \\ London School of Economics \\ and IZA Bonn \\ Dirk Sliwka \\ University of Cologne \\ and IZA Bonn
}

\section{Discussion Paper No. 1758 \\ September 2005}

\author{
IZA \\ P.O. Box 7240 \\ 53072 Bonn \\ Germany \\ Phone: +49-228-3894-0 \\ Fax: +49-228-3894-180 \\ Email: iza@iza.org
}

\begin{abstract}
Any opinions expressed here are those of the author(s) and not those of the institute. Research disseminated by IZA may include views on policy, but the institute itself takes no institutional policy positions.
\end{abstract}

The Institute for the Study of Labor (IZA) in Bonn is a local and virtual international research center and a place of communication between science, politics and business. IZA is an independent nonprofit company supported by Deutsche Post World Net. The center is associated with the University of Bonn and offers a stimulating research environment through its research networks, research support, and visitors and doctoral programs. IZA engages in (i) original and internationally competitive research in all fields of labor economics, (ii) development of policy concepts, and (iii) dissemination of research results and concepts to the interested public.

IZA Discussion Papers often represent preliminary work and are circulated to encourage discussion. Citation of such a paper should account for its provisional character. A revised version may be available directly from the author. 


\title{
ABSTRACT
}

\section{Incentives, Decision Frames, and Motivation Crowding Out - An Experimental Investigation*}

\begin{abstract}
A simple principal agent problem is experimentally investigated in which a principal repeatedly sets a wage and an agent responds by choosing an effort level. The principal's payoff is determined by the agent's effort. In a first setting the principal can only set a fixed wage in each period. In a second setting the principal has the possibility to supplement the fixed wage with a piece rate. Surprisingly, efforts are lower in the case where piece rates can be paid. Furthermore, switching in the same treatment from a setting where piece rates are available to one where only fixed wages can be paid tends to lead to even lower effort levels. Based on our findings we suggest a new explanation for motivation crowding out by arguing that the use of piece rates considerably alters the principals' and agents' perception of the situation.
\end{abstract}

JEL Classification: C91

Keywords: incentives, crowding-out, reciprocity, reputation, experiment

Corresponding author:

Bernd Irlenbusch

London School of Economics

Houghton Street

London, WC2A 2AE

United Kingdom

Email: b.irlenbusch@Ise.ac.uk

* Financial support by the Deutsche Forschungsgemeinschaft through grants KR2077/2-1, KR2077/23, IR43/1-1 and the European Union through the EU-TMR Research Network ENDEAR (FMRX-CT980238) is gratefully acknowledged. 


\section{Introduction}

Almost all principal-agent models imply that appropriate performance contingent monetary incentives have to be provided in order to motivate agents to exert effort. A growing number of studies, however, indicate that the provision of monetary incentives does not necessarily lead to an increase in effort. In fact it has been observed that incentives can even reduce the endeavors of those who were meant to become motivated. So far the mechanisms which drive such crowding out effects, as they are termed by Frey (1997), still constitute a largely unresolved puzzle. Compelling evidence in favor of crowding out effects has recently been provided by Gneezy and Rustichini (2000a, b). By conducting inventive field experiments they show for example that students who collect donations for charity programs perform better when they receive no monetary reward at all compared to those who are paid a small bonus proportional to the amount they collect. To some extent these observations can be explained by an approach put forward by psychologists, according to which an activity can have a motivation of its own, called intrinsic motivation, which leads to the execution of the activity in the absence of rewards. It is stated that intrinsic motivation may be diminished by extrinsic incentives like performance contingent monetary rewards. ${ }^{1}$

A second strand of evidence, which suggests that monetary incentives may crowd out voluntary effort contributions, comes from laboratory experiments, in which effort choices are typically represented by abstract numbers. In such a setting intrinsic motivation can be assumed to be negligible and therefore if a crowding out effect would be observed a different mechanism than the one mentioned above must be at work. On the one hand there exists overwhelming evidence that reciprocity and fairness play an important role in employment relationships indicating that fixed wages may motivate agents quite well to cooperatively exert effort. Several studies indeed show that agents are willing to reciprocate generous wages with remarkably high effort levels (for example Fehr, Kirchsteiger and Riedl (1993), Fehr, Gächter and Kirchsteiger (1997), Charness (2004), Brandts and Charness (2004), Charness and Dufwenberg (2004)). On the other hand fairness and reciprocity are known to be relatively fragile in the presence of explicit incentives. This is especially true if incentives are provided via a threat of punishment. Fehr and Rockenbach (2003) impressively show that if a

\footnotetext{
1 See for example Deci (1971), Lepper, Greene, and Nisbett (1973), Deci, Koestner, Ryan (1999). For an overview on experimental studies see for instance Pittmann and Heller (1987), Wiersma (1992), and Tang and Hall (1995). However, the argument that extrinsic motivation crowds out intrinsic motivation is not undisputed among psychologists, see e.g. Cameron and Pierce (1994) and Eisenberger and Cameron (1996).
} 
principal deliberately chooses a punishment incentive scheme, performance of agents is considerably reduced. An analogous but weaker effect of performance crowding out is reported in Fehr and Gächter (2002). They find that even the promise of a performance contingent reward of a fixed size may undermine voluntary effort contributions. ${ }^{2}$ Gneezy and Rustichini (2000a), Manthei (2004) and Gneezy (2005) report persuasive evidence that extrinsic incentives influence effort in a non-monotonic way: While relatively small monetary incentives bear the potential to crowd out motivation, relatively large ones increase effort at least as long as the resulting wages are below a certain reference level.

In the present study we aim at contributing to the understanding of crowding out effects in ongoing principal agent relations. ${ }^{3}$ We design an experiment to explore a new possible explanation for why extrinsic incentives might crowd out effort. In particular we are interested in the influence the compensation scheme of piece rates may have on the agents' cognitive perception of the situation. A possible conjecture would be that the availability of piece rate incentives leads agents to follow a short term, individual maximization behavior, whereas fixed wages may cause them to pursue a more cooperative, longer term orientation.

In our laboratory experiment a principal repeatedly proposes a wage to an agent who in return decides on how much effort to exert by choosing an abstract number. In the baseline setting (pure fixed) the principal is restricted to offer a pure fixed wage while he can choose between a pure fixed wage and a piece rate scheme in the control setting (choice). To our best knowledge so far no crowding out effects of piece rate schemes have been reported in such an abstract laboratory environments, in which the impact of intrinsic motivation can almost be excluded. Prendergast (1999, p.18) highlights that the incentive effect of compensation on performance appears to "be most plausible for activities where little intrinsic motivation is evident without explicit incentives." By comparing the effort levels in our two treatments, however, we find a surprisingly clear crowding out effect i.e. effort turns out to be considerably lower in the treatment where explicit incentives are available. Profits and welfare are also higher in the case where only fixed wages are possible. Interestingly,

\footnotetext{
2 For similar results see Frey and Oberholzer-Gee (1997), Bohnet, Frey and Huck (2001), Frey and Jegen (2001), Fehr and Falk (2002), Fehr, Klein and Schmidt (2004), Fehr and List (2004), Falk and Kosfeld (2004), Gächter, Königstein, Kessler (2005). The crowding-out literature is surveyed by Bowles (2005).

3 Excellent overviews about theoretical and empirical findings on various incentive schemes are provided by Gibbons (1998), Lazear (1999) and Prendergast (1999). For interesting field studies that tend to support the performance increasing effect of piece rate schemes see Paarsch and Shearer (1999), Lazear (2000), Paarsch and Shearer (2000), Shearer (2004) and Freeman and Kleiner (2005). Illuminating laboratory experiments investigating piece rate schemes are conducted by Bull, Schotter, Weigelt (1987) and Anderhub, Gächter, Königstein (2002)
} 
however, when only examining the choice setting our results are remarkably well explained with a standard neoclassical model: Contract choices and efforts converge to the equilibrium prediction. These results are well in line with the explanation that piece rates lead agents to short-term, individual maximization behavior.

A second goal of our study is to examine a possible persistence of this effect. Does the experience with a certain payment scheme affect the perception of a different scheme introduced afterwards? Some previous studies already indicate that the behavior induced by various institutional arrangements has an afterglow even if these institutions actually are no longer in operation. Gneezy and Rustichini (2000b) conduct a clever field study by introducing an incentive structure consisting of a monetary fine for late-coming parents in day-care centers. Quite surprisingly as a result the number of late-comers increases. Apparently the fine is considered to be a price for being late. Even more surprisingly, this crowding out effect persists after the fine is removed. In the same direction Bohnet and Huck (2004) report persuasive experimental evidence according to which the institution of a repeated fixed partner matching fosters trust and trustworthiness even in the long run when the partner institution is not available anymore. ${ }^{4}$

To investigate the influence of previous experience with a certain payment scheme the experiment is followed by a second part, in which those agents who take part in the pure fixed setting in the first part continue with the choice setting where incentive schemes are allowed and vice versa. Comparing the results from both settings in the two parts, we indeed find strong evidence for the persistence of the effect: Efforts, profits and welfare are larger if individuals have previously experienced an employment relation with pure fixed wages and then continue with the choice setting as compared to those who start with the possibility to receive a performance contingent wage right from the beginning and afterwards work under pure fixed wages. This indeed provides evidence for a possible change in the agents' cognition of the situation. In addition this view is strongly supported by results from a postexperimental questionnaire.

\footnotetext{
${ }^{4}$ Similar observations are presented in other studies. Van Huyck, Battalio and Beil (1991) report that common experience of accidentally chosen strategies in multiple equilibria games is likely to determine future play although other payoff dominating equilibria exist. Nalbantian and Schotter (1997) show that participants who experienced free-riding in a voluntary contribution setting subsequently tend to continue exerting low effort levels even if various group incentive schemes like team competition or monitoring are introduced. Gächter, Königstein, Kessler (2005) find that the crowding out effects of punishment and reward incentive schemes also persist after the schemes have been changed.
} 
The paper proceeds as follows. In section 2 a simple principal agent model is analyzed and the subgame perfect equilibrium is determined. In section 3 we derive alternative predictions of behavior. Section 4 describes the experimental design and procedure. Section 5 a set of testable hypotheses is developed and Section 6 reports our experimental results. Section 7 concludes.

\section{A Simple Principal Agent Model}

Consider the following simple principal agent model. A principal is matched with an agent for $T$ periods. In each period the agent can choose an effort level $e_{t}$ for which he incurs costs $c\left(e_{t}\right)=\frac{c}{2} e_{t}^{2}$. With this effort he produces an output of $k \cdot e_{t}$ received by the principal. We compare two settings. In a first setting the principal can only determine a fixed wage $\alpha_{t}$ in the beginning of each period paid to the agent before he chooses his effort level. Hence, the principals overall payoff in a period $t$ is

$$
k \cdot e_{t}-\alpha_{t}
$$

and the agent receives

$$
\alpha_{t}-\frac{c}{2} e_{t}^{2}
$$

In a second setting, the principal can choose between either setting a fixed wage or selecting a output dependent incentive scheme in the beginning of each period. When she decides to select an incentive scheme she has to pay a fee $f$. The fee $f$ represents the costs of performance measurement.

After having chosen the type of compensation, the principal can determine its size. If she has chosen a fixed wage she just has to determine $\alpha_{t}$, the agent chooses his effort level and the payoffs are given as above in (1) and (2).

If she has chosen an incentive scheme instead, she has to determine a fixed wage $\alpha_{t}$ and a piece rate $\beta_{t}$. We assume that both $\alpha_{t}$ and $\beta_{t}$ have to be non-negative, which corresponds to a limited liability assumption in standard principal agent theory. Now, the agent receives in addition to $\alpha_{t}$ a payment of $\beta_{t} \cdot k \cdot e_{t}$ from the principal. The principal's payoff in a period $t$ is therefore 


$$
\left(1-\beta_{t}\right) k \cdot e_{t}-\alpha_{t}-f
$$

and the agent receives

$$
\alpha_{t}+\beta_{t} \cdot k \cdot e_{t}-\frac{c}{2} e_{t}^{2}
$$

The solution for the stage game with pure fixed wages is very simple if we assume rational and self-interested behavior. The agent will never exert any effort and the principal will not set positive wages. Both principal and agent earn nothing. In the first setting, this stage game is repeated for $T$ periods and by backward induction the prediction is the same for each stage. Now we analyze the subgame perfect equilibrium in a period where the principal has decided to set up an incentive scheme. For a given incentive scheme, the agent maximizes expression (4). Solving the first order condition for $e_{t}$ yields

$$
e_{t}=\frac{\beta_{t} \cdot k}{c}
$$

We can now go back to the first stage where the principal specifies $\alpha_{t}$ and $\beta_{t}$. She will of course never choose a positive value of $\alpha_{t}$ as this will only reduce her own payoff without improving incentives. To compute the optimal value of the piece rate $\beta_{t}$ we insert (5) in the principal's payoff function (3)

$$
\max _{\beta_{t}}\left(1-\beta_{t}\right) k \cdot \frac{\beta_{t} \cdot k}{c}-f .
$$

Solving the first order condition of this problem for $\beta_{t}$ yields the simple prediction that the principal chooses $\beta_{t}=\frac{1}{2}$ whatever the values of $k$ and $c$. Hence, it is optimal to share half of her profits with the agent. The equilibrium effort level is then

$$
e_{t}^{*}=\frac{k}{2 c}
$$

Note that we did not allow negative values for $\alpha_{t}$ and therefore "sell the shop" contracts where the agent is residual claimant are infeasible. Hence, the optimal contract does not attain the first best solution. The efficient effort level would be chosen such as to maximize the total payoff of principal and agent and is twice as high as the equilibrium effort

$$
e_{t}^{F B}=\frac{k}{c}
$$

The principal's overall equilibrium payoff when choosing the incentive scheme is therefore 


$$
\frac{k^{2}}{4 c}-f
$$

When $\frac{k^{2}}{4 c}>f$ it will always be optimal for the principal to choose the incentive scheme. For this case theory yields the clear-cut prediction that the principal will never choose a pure fixed wage in the setting where she had the choice between fixed wage and an incentive scheme. Furthermore we should expect that effort levels and the principal's profits are higher when she can choose an incentive scheme.

Finally, note that the agent's expected profit is positive due to our limited liability assumption. It is given by $\frac{1}{2} k \frac{k}{2 c}-\frac{c}{2}\left(\frac{k}{2 c}\right)^{2}=\frac{k^{2}}{8 c}$.

\section{Alternative Predictions of Behavior}

We will now discuss possible theoretical foundations to back an alternative set of hypotheses that we will formulate precisely after we explain the experimental design.

\subsection{Sanctions in Repeated Games}

It is often argued that behavior observed in finitely repeated games in the laboratory can to some extent be better explained by infinite horizon models at least up to the last rounds (compare e.g. Selten and Stoecker 1986). Furthermore, it is well known that in an infinitely repeated game, more efficient equilibria may be attainable, where the principal offers a high fixed wage and the agent chooses an effort level which is higher than the second best level in each period. This equilibrium can be sustained with a trigger strategy such that each of the players deviates only when the other one previously has.

Baker, Gibbons and Murphy (1994) and Schmidt and Schnitzler (1995) have shown that the possibility of setting explicit incentives makes it harder to establish such an implicit or relational contract enforced by infinitely repeated interaction. The reason is that the possibility of a credible punishment is reduced when incentive contracts are feasible.

It can easily be shown that a similar effect arises if the model laid out above would be infinitely repeated. To do this, we check which combinations of a fixed wage $\alpha$ and an effort level $e$ can be sustained in an infinitely repeated game for both settings when both play a trigger strategy where the static Nash equilibrium is played after any deviation. 
When only fixed wages can be paid, the static Nash equilibrium leads to profits of 0 for both, principal and agent. Given a wage $\alpha$ the agent will choose effort level $e$ instead of deviating to zero effort, if

$$
\frac{1}{1-\delta}\left(\alpha-\frac{c}{2} e^{2}\right) \geq \alpha \quad \Leftrightarrow \quad \alpha \geq \frac{c}{2 \delta} e^{2}
$$

The principal will pay wage $\alpha$ if $k e \geq \alpha$. Hence, the equilibrium can be sustained when

$$
k e \geq \alpha \geq \frac{c}{2 \delta} e^{2}
$$

When the principal can also choose an incentive scheme, the static Nash equilibrium yields payoffs $\frac{k^{2}}{4 c}-f$ for the principal and $\frac{k^{2}}{8 c}$ for the agent. Given a wage $\alpha$ the agent will choose effort level $e$, if

$$
\frac{1}{1-\delta}\left(\alpha-\frac{c}{2} e^{2}\right) \geq \alpha+\frac{\delta}{1-\delta} \frac{k^{2}}{8 c} \quad \Leftrightarrow \quad \alpha \geq \frac{c}{2 \delta} e^{2}+\frac{k^{2}}{8 c}
$$

The principal will stick to the fixed wage $\alpha$ instead of the optimal incentive scheme if

$$
k e-\alpha \geq \frac{k^{2}}{4 c}-f \quad \Leftrightarrow \quad k e-\left(\frac{k^{2}}{4 c}-f\right) \geq \alpha .
$$

Hence, the equilibrium can be sustained when

$$
k e-\left(\frac{k^{2}}{4 c}-f\right) \geq \alpha \geq \frac{c}{2 \delta} e^{2}+\frac{k^{2}}{8 c}
$$

Both, the principal and the agent lose less when cooperation fails, when it is feasible to choose a piece rate incentive scheme. Hence, both have a stronger incentive to defect. Of course in both cases there is a continuum of equilibria. But, the set of parameters where cooperation can be sustained in equilibrium is strictly smaller when incentive schemes are feasible.

Still, when the players do not discount future income too much it is straightforward to check that the first best solution can be attained with pure fixed wages in both settings.

\subsection{Cognitive Perception of the Relationship}

There are some indications from empirical research that economic choices are well affected by the actor's decision frame where the latter according to Tversky and Kahneman (1981), 
refers "to the decision maker's conception of acts, outcomes, and contingencies associated with a particular choice." Many experiments have shown that people's choices are affected by the framing of the situation.

As Tversky and Kahneman (1986, p. 257) point out, "framing is controlled by the manner in which the choice problem is presented as well as by norms, habits, and expectancies of the decision maker." Hence, the choice of a compensation scheme will in itself have an impact on the agent's cognitive perception of the situation and therefore may affect his current behavior beyond the direct economic incentive impact of the scheme. Moreover, the past experience with a compensation scheme will affect the perception of the work relationship in the future. ${ }^{5}$ A possible conjecture is that the choice of an incentive scheme may lead agents to adopt an individual maximization frame under which individuals tend to focus on the maximization of current payoffs rather than a cooperative frame, where they may be guided towards a more cooperatively oriented or reciprocal behavior.

When the players cannot use incentive schemes but are restricted to pure fixed wages, they can only create a surplus when they act cooperatively. However, when being confronted with incentive schemes right away, then a surplus can be created even within the individual maximization frame. This idea is related to Kohn's (1993) informal discussion of the disadvantages of incentive plans: “'Do this and you'll get that' [..] focuses attention on the 'that' instead of the 'this'. [..] Do rewards motivate people? Absolutely. They motivate people to get rewards."6

But one can also give a game theoretic interpretation of the notion of decision frames. Recall that there are multiple equilibria in the repeated game. Therefore the different perception of the situation is closely related to the problem of equilibrium selection in a repeated game: The equilibrium in which the static Nash behavior is repeatedly chosen, which is of course also subgame perfect, puts principal and agent in a situation where it is optimal only to consider the returns from the current period. In a cooperative equilibrium, however, players cooperate because this will be rewarded by future cooperation of the other player. Hence, a possible prevalence of an individual maximization frame when piece rates are paid corresponds to the case where both players fail to coordinate to the more efficient equilibrium. It seems to be

\footnotetext{
${ }^{5}$ March (1994, p.14f) for instance argues: "There is a tendency for frames to persist over a sequence of situations."

${ }^{6}$ The influence of decision frames in a social dilemma has already been demonstrated in a questionnaire study by Tenbrunsel and Messick (1999). They find that the presence of a sanctioning mechanism alters the decision frame to a less cooperative one. The authors argue that this perceived difference in the decision frames is ultimately the reason for the observed reduction in contribution if sanctions become available.
} 
much easier to coordinate on the cooperative equilibrium in the pure fixed wage setting, as no surplus at all can be attained if the process of coordination fails when only fixed wages are feasible.

The notion of decision frames as a means of equilibrium selection is closely related to the idea of a focal point (compare Schelling 1980) or a convention (compare Sugden 1989). Schelling (1980, p.291) argues that efficiency considerations may well induce decision makers to select payoff dominant equilibria. According to Sugden (1989, p.86) "the essential feature of a convention is that it is one of several possible solutions to a game." When a convention evolves to coordinate behavior, players draw on ideas they have in common and "The most important source of such ideas [..] is common experience." Sugden (1989, p.90). From this angle, the past experience of explicit incentives may make it harder to establish a convention requiring reciprocal behavior and cooperative play.

\section{Experimental Design and Procedure}

The experiment was conducted in the Laboratorium für experimentelle Wirtschaftsforschung $(e L a b)$ at the University of Erfurt. In total 84 students participated - most of them were enrolled in the Faculty of Law, Economics, and the Social Sciences. Two treatments were implemented. For each of the two treatments we conducted two sessions with 24 participants in the first and 18 in the second session of each treatment. Participants were allowed to take part only once and only in one of the two treatments. A session consisted of two parts with 20 identical periods in each part and lasted for about one and a half hours. During the session payoffs were given in our fictitious experimental currency "Talers". After a session payoffs were converted to $€$ and paid in cash with an exchange rate of $6 €$ for 100 Talers.

At the outset of a session the instructions were handed out and read aloud by the experimenters. In addition the participants were advised how to use the experimental software. ${ }^{7}$ In order to reduce the influence of uncontrollable connotations the strategic situation of the experiment was presented in completely neutral terms. Terms like "principal" or "agent" were avoided, instead the roles were referred to as players of type A (principals) and type B (agents). We spoke of "transfers" instead of "wages" and instead of "effort" a "number" could be selected. After the instructions were read all participants took seat in a

\footnotetext{
${ }^{7}$ A translation of the instruction sheet is given in the appendix - the original German text is available from the authors on request. The experimental software was developed by making use of the toolbox zTree (Fischbacher 1999).
} 
cubicle with the number they had previously drawn on a card. The computer software matched participants into pairs randomly and anonymously. Half of the participants were assigned the role of a principal and the other half the role of an agent. Pairs and roles were fixed during the whole experiment. Thus, we collected 21 independent observations for each treatment. Communication other than over the experimental software was not allowed.

Each treatment consisted of two parts. In each part of a treatment we either implemented a setting in which only fixed wages could be set for 20 periods or another setting where the principals could choose between a fixed wage and an incentive scheme in the beginning of each of the 20 periods. In the first treatment we started with the pure fixed setting in the first part and switched to the choice setting in the second part. In the second treatment the reverse order was implemented. In the beginning of each session only the first part was explained. Although the participants knew that there would be a second part they did not know of what kind the experiment would be in that second part.

Figure 1: Experimental design

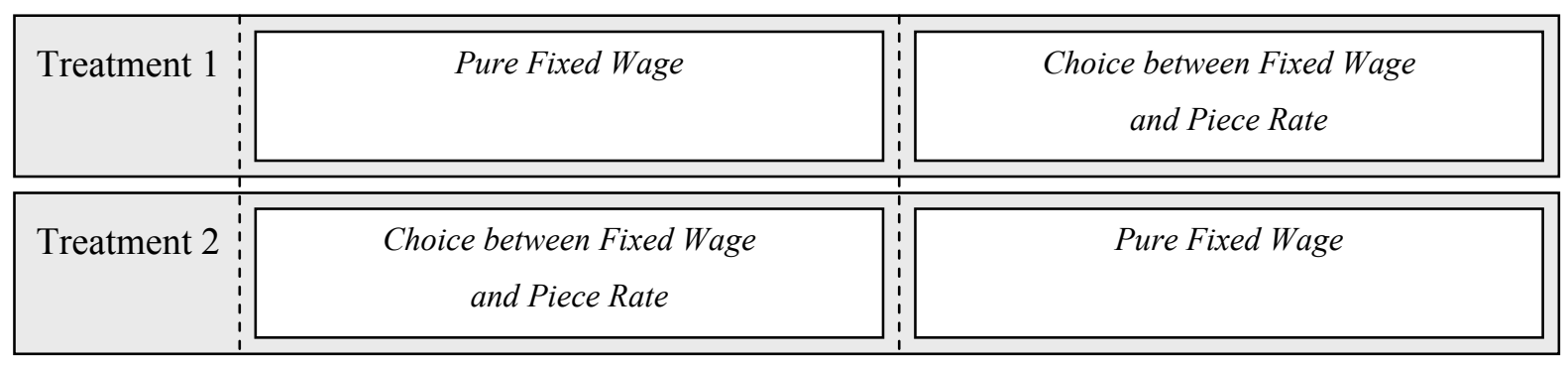

Part 1

Part 2

In the pure fixed setting each principal chose in the beginning of each period a wage level from the integer set $\{0, \ldots, 40\}$ which was directly transferred from her account to that of the agent assigned to her. After this the respective agent had to choose an effort level from the integer set $\{0, \ldots, 20\}$. Then the output was determined by simply doubling the effort level. ${ }^{8}$ Thus, the total payoff for the principal was defined as output minus wage. The total agent's payoff was the wage minus the $\operatorname{cost}^{9}$ for the chosen effort level. The costs were determined by a quadratic cost function with $c=1 / 6$ in our model. This procedure was repeated 20 times with unchanged principal-agent pairs.

\footnotetext{
${ }^{8}$ Therefore, the value of the variable $k$ in our theoretical model is 2 in the experiment.

9 The cost function for agents' efforts is shown in the appendix as it was provided to all participants.
} 
In the choice setting in each period the principal could first choose whether to set a fixed wage or to implement an incentive scheme consisting of a fixed wage and a variable rate. The agent was informed about this decision. When a principal did choose a fixed wage the period proceeded exactly as in the pure fixed setting. When choosing the incentive scheme the principal incurred a cost of 2 Talers ${ }^{10}$ which were directly subtracted from her account and she had to specify a fixed payment from the integer set $\{0, \ldots, 40\}$ and to chose a variable rate from the set $\{10 \%, 20 \%, \ldots, 100 \%\}$. The fixed payment was directly transferred from the principal's to the agent's account. After this, again the respective agent had to choose an effort level from the integer set $\{0, \ldots, 20\}$ and the output was determined by doubling the effort level. But now the agent received the specified variable share of the output produced and the principal only kept the remaining part of the output. Table 1 summarizes the parameter values.

Table 1: Parameter Values

\begin{tabular}{lc}
\hline \hline Initial capital balance of principals & 100 \\
Initial capital balance of agents & 100 \\
\# independent observations & 21 \\
\# rounds per treatment & 40 \\
\# rounds per setting & 20 \\
Integer set of effort levels & $\{0, \ldots, 20\}$ \\
Integer set of fixed wages & $\{0, \ldots, 40\}$ \\
Variable rates & $10 \%, 20 \%, \ldots, 100 \%\}$ \\
Efficient effort & 12 \\
Equilibrium wage in pure fixed & 0 \\
Equilibrium effort in pure fixed & 0 \\
Equilibrium fixed wage in choice & 0 \\
Equilibrium piece rate in choice & $50 \%$ \\
Equilibrium effort in choice & 6 \\
\hline \hline
\end{tabular}

After finishing all 40 rounds participants were asked to fill in a questionnaire regarding their reasons and motivations to choose wages and effort levels, respectively.

\section{Hypotheses}

If agents act purely selfish and rational then clear-cut predictions for the experiment can been derived from the simple principal agent model. First of all, effort levels should be larger when

${ }^{10}$ Hence, this corresponds to a value of $f=2$ in our theoretical model. 
piece rates are feasible. But furthermore, this optimal effort levels should be independent from the history experienced by the agents. Recall that the equilibrium prediction for the choice setting was a fixed wage of zero and a variable rate of $50 \%$. The cost function was chosen such that the equilibrium effort level is equal to 6 .

\section{Hypothesis 1 (Rationality and Self-Interest):}

$e_{\text {ChoicePart } 1}=6>e_{\text {FixedPart }}=0$

If however, as many experiments so far have shown, some players don't act selfishly and for instance are guided by fairness or reciprocity, agents will on average respond to positive wages by choosing positive effort levels in the fixed wage setting and principals may therefore have an interest indeed to offer positive wages. But note that when behavior can be described by modeling rational utility maximization with distributional social preferences ${ }^{11}$, as for instance inequity aversion, we should still observe effort levels that are higher in the choice setting as the principals can always emulate pure fixed wages in this case and should do so, when it would make them better off. This leads to the following hypothesis.

\section{Hypothesis 2 (Social Preferences):}

$e_{\text {ChoicePart1 }} \geq e_{\text {FixedPart1 }}>0$.

But if the perception of the situation is affected by the offered incentive scheme and therefore the player's decision frame is altered, this may lead to different predictions. First, consider the pure fixed wage treatment. If a player is purely selfish, he or she will choose an effort level of zero. But in this case no profits can be generated at all. Hence, a player can naturally be guided towards a cooperative understanding of the situation as any surplus can only be generated by cooperative or reciprocal behavior. As the repeated nature of the situation gives the mutual possibility for sanctions or rewards this may even lead to effort levels that come close to the efficient outcome (which was equal to 12 in our case).

If however, the players are confronted with the choice setting (i.e. principals and agents know that piece rates can be offered) this may no longer be the case. A surplus can now be generated even when players pursue only short-term selfish motives and try to maximize the current payoff. Agents may then learn the (selfishly) optimal behavior over time and may be guided towards solution of the principal agent model.

\footnotetext{
${ }^{11}$ See for instance the models by Levine (1998), Fehr and Schmidt (1999), Bolton and Ockenfels (2000), Charness and Rabin (2002) and others.
} 
Note that the effort level of 6 , that would be attained in this case, is far lower then the efficient level of 12 . If the formation of a cooperative frame works quite well, then it may therefore even be the case that fixed wages lead to higher effort levels than the possibility of setting piece rates in the choice setting. It is in this way a crowding-out effect may appear in our setting.

As laid out above, a similar observation might also be backed with purely selfish and rational agents by referring to infinitely repeated game as the feasibility of piece rates makes punishing non-cooperative behavior less credible. Hence, both explanations would support the following hypothesis:

\section{Hypothesis 3 (Cognitive Frames/Repeated Games and Sanctions):}

$e_{\text {FixedPart1 }}>e_{\text {ChoicePart1 }}$.

But the switch of settings in our experiment allows a test of the explanation based on a shift in the cognitive perception of the situation against the explanation based on sanctions in repeated games.

As we argued above, those players who started with pure fixed wages should be able to establish a cooperative frame more easily. When they continue to work under the choice setting in the second part they then have already experienced that fixed wages may lead to efficient outcomes (and therefore higher payoffs for principals and agents). Hence, groups who fared well with fixed wages in the first part, could continue to work with pure fixed wages also in the second. Effort levels in the choice setting should then be higher when the players have worked with pure fixed wages before.

Furthermore, if players have experienced the choice setting in the beginning and therefore have established an individual maximization frame, this may carry over to the second part when only fixed wages are available. As they have learned that even with short-term oriented selfish behavior a positive surplus can be generated, it may then become harder to establish a cooperative frame in the second part. We can summarize these predictions in the following hypothesis: 


\section{Hypothesis 4 (Persistence of Cognitive Frames):}
(a) $e_{\text {ChoicePart2 }}>e_{\text {ChoicePart1 }}$
(b) $e_{\text {FixedPart1 }}>e_{\text {FixedPart2 }}$.

If the feasibility of sanctions in repeated games is of high importance, then we should not observe too large differences within each setting across the two treatments. But more importantly, we may observe that switching from a choice setting to a pure fixed wage setting leads to higher effort levels at least in the beginning of the second part as sanctioning noncooperative behavior then becomes easier. For the same reason we may observe reduced effort levels, when the possible choice of a piece rate is introduced in part 2.

\section{Hypothesis 5 (Repeated Games and Sanctions):}
(a) $e_{\text {FixedPart } 1}>e_{\text {ChoicePart2. }}$
(b) $e_{\text {ChoicePart1 }}<e_{\text {FixedPart2 }}$

\section{Results}

\subsection{Fixed Wages or Incentive Schemes}

We start by focusing on the first part in both treatments. We compare the pure fixed setting in which principals could offer only fixed wages to choice setting where they had the additional possibility to set up linear incentive schemes.

Hypothesis 1 and 2 are concerned with the comparison of effort levels across both treatments. The first interesting experimental observation is that average effort levels in the choice setting across all rounds are 6.25 which is well in line with the first part of hypothesis 1a as the effort level is surprisingly close to the equilibrium prediction of 6 . Hence, it may well be the case that the principal agent model laid out above can quite accurately explain the observed behavior.

However, this picture changes when we compare this to the outcome of the fixed wage setting. Figure 2 shows the time-series of average effort levels across the 20 periods of the first part in both treatments. Note that the average effort levels are 9.15 in the pure fixed setting and therefore much closer to the efficient level of 12 than those in the choice setting. 


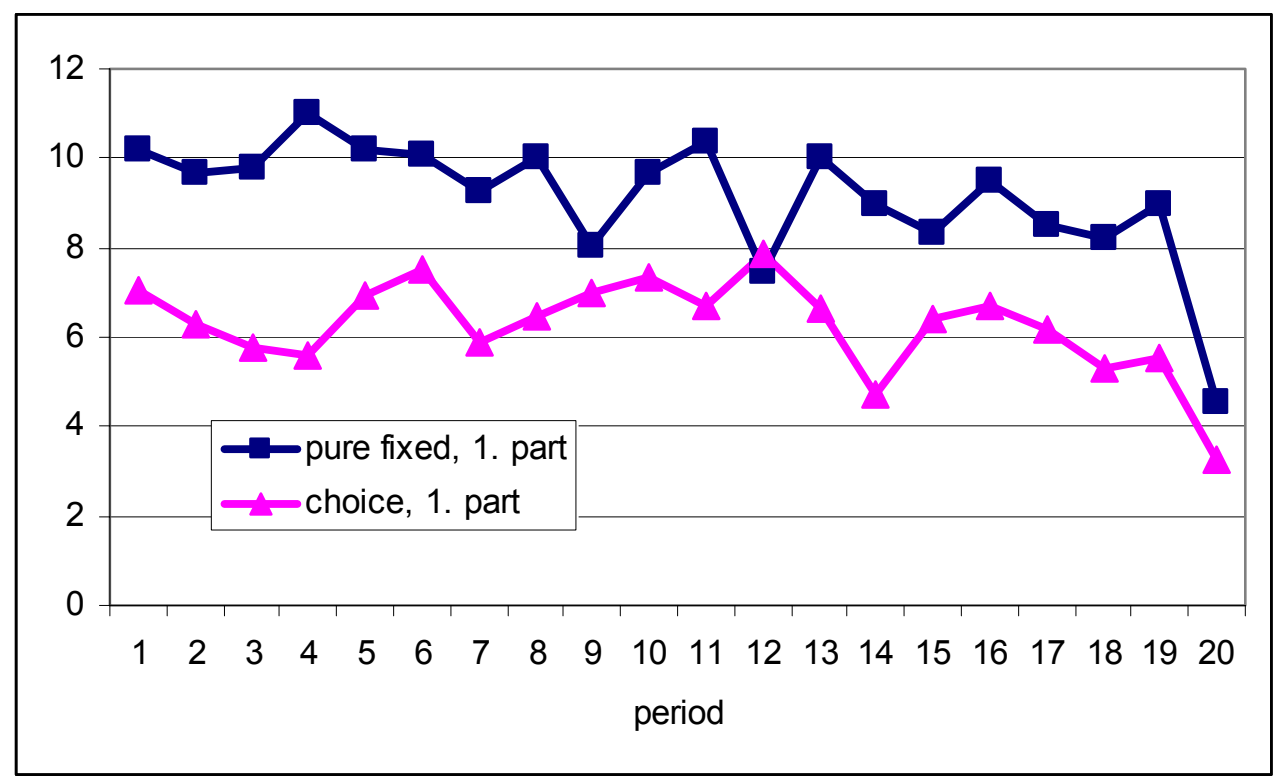

Figure 2: Average efforts in Part 1 of both Treatments.

The difference is weakly significant (Mann-Whitney $\mathrm{U}$ test, $p=6.1 \%$, two-tailed). Hence, we indeed observe a crowding out effect when both settings are compared. It is the additional policy option to choose a performance contingent wage that seems to lead to reduced effort levels.

This also has a strong impact on the principals' profits which are 2.98 in the pure fixed setting but only 0.69 when the principal has the additional option to set up an incentive scheme. This difference is highly significant ( $p=0.5 \%$, Mann-Whitney $U$ test, two-tailed). We can also contrast both treatments in terms of efficiency by comparing the average total profits per group. With fixed wages only it is 7.68 , with the choice possibility only 6.02 . This difference is highly significant (Mann-Whitney U Test, $p=0.9 \%$, two-tailed). ${ }^{12}$ Therefore, it is not only from the principal's point of view, that pure fixed wages are preferable in our experiment, but also from a welfare perspective. We can conclude:

\section{Experimental Observation 1 (A Comparison of both Settings in the First Part):}

In the choice setting as first part of the experiment the observed average effort levels of 6.25 are well in line with the equilibrium prediction of the static principal agent model (effort level of 6) with self interested rational agents. But observed effort levels and wages in the fixed wage setting (9.15) exceed not only the theoretical prediction of 0 but even those in the choice

\footnotetext{
${ }^{12}$ The profits of the agents are (insignificantly) higher in the choice setting (5.33) than with fixed wages only (4.71).
} 
setting. The principal's profits and total profits are significantly higher when only fixed wages are feasible.

Note that this observation contradicts hypothesis 1 as well as hypothesis 2 . Recall that the principal is always able to pay a pure fixed wage in the choice setting. Hence, simple theories of social preferences alone cannot explain this observation. If a fixed wage for instance would lead to more reciprocal behavior and therefore higher effort levels the principals could have always made use of this in the choice setting. However, the observation is well in line with hypothesis 3. Before we investigate this further it is quite instructive to consider the data from the choice setting alone to analyze whether the mechanisms of the simple principal agent model indeed may explain that average efforts are so close to the equilibrium effort level.

\subsection{A Closer Look at the Choice Setting}

It is quite interesting to take a look at the chosen contracts in the choice setting. Recall that from our theoretical analysis in section 2 we would expect that principals propose incentive contracts with a fixed wage of zero and a piece rate of $50 \%$. In fact the actually observed development of these two figures over rounds comes astonishingly close to this expectation as can be seen from Figure 3: On average fixed wages converge close to zero while the average piece rate approaches $50 \%$ in the last rounds.

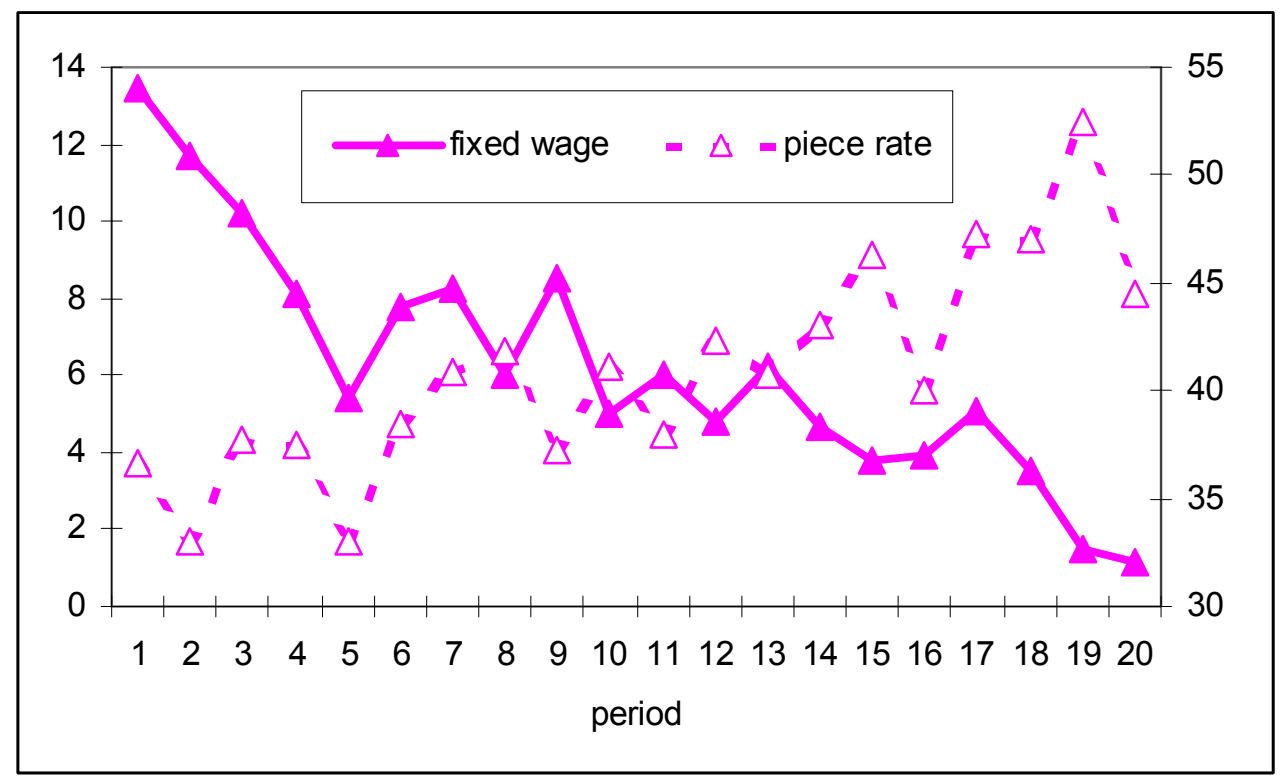

Figure 3: Average fixed wages and piece rates in the Choice Setting in Part 1

From equation (5) we know that rational agents respond on an increase of the piece rate by $10 \%$ with an effort increase of 1.2 units (recall that $k / c=12$ ). To examine how agents react to 
variations in the piece rate we conducted Tobit regressions ${ }^{13}$ with effort as the dependent variable (compare Table 2).

Table 2: Tobit-Regressions with effort as dependent variable (choice setting, 1. part)

\begin{tabular}{lccc}
\hline & 1 & 2 & 3 \\
\cline { 2 - 4 } Wage & $0.384^{* * *}$ & $0.401^{* * *}$ & $0.345^{* * *}$ \\
& $(0.052)$ & $(0.025)$ & $(0.025)$ \\
Bonus & $0.110^{* * *}$ & $0.112^{* * *}$ & $0.078^{* * *}$ \\
& $(0.033)$ & $(0.009)$ & $(0.011)$ \\
LastPeriod & $-3.433^{* *}$ & & \\
Constant & $(1.374)$ & & \\
Period Dummies & 0.925 & & Yes \\
Fixed effects (Groups) & $(0.738)$ & Yes & Yes \\
\hline
\end{tabular}

Standard errors are given in parentheses. In regression 1 and 2 these are robust standard errors.

* significant at $10 \%$;* significant at $5 \%$; ** significant at $1 \%$

It is quite interesting to see that the regression results are again well in line with the theoretical prediction: according to regression 1, agents react to a $10 \%$ increase of the piece rate with an effort increase of 1.1 units. ${ }^{14}$ The within group effect is somewhat smaller as can be seen from the third row where fixed effects were included.

From these considerations we can conclude:

\section{Experimental Observation 2 (Contracts and Agents' Reactions in the Choice Setting):}

The contracts offered in the choice setting converge towards the equilibrium prediction of a fixed wage of 0 and a piece rate of 50\%. Moreover, the slope of the agents reaction function to a chosen piece rate is close to the theoretically predicted rate.

Note that in contrast to the predictions based on the agency model, the base wage has also a significant effect on the effort exerted. Hence, a reciprocity motive is present in the agents'

13 Applying Tobit regressions appears to be adequate because effort choices of 0 are frequently observed. In the regressions without fixed effects we report robust standard errors. Table 2 reports the marginal effects on the latent variable of the Tobit model. Estimations of the marginal effects $\partial \mathrm{E}[e \mid \beta] / \partial \beta$ on the censored variable yield rather similar values for all three considered estimation models.

14 These observations are well in line with experimental results by Anderhub, Gächter and Königstein (2002), who have examined linear compensation schemes without comparing them to pure fixed wages. They also have found that the impact of the variable rate on effort is remarkably similar to the theoretical prediction which in their case encompassed a variable rate of $100 \%$ as they allowed for negative fixed wages. 
effort choices and the principals cannot only raise effort levels by raising the piece rate but also by raising the base wage. However, raising the base wage was not worthwhile for the principals as a wage increase by one unit only raised revenues by 0.768 units. This explains why base wages converge to zero during the game.

\subsection{What Makes Pure Fixed Wages Superior?}

In order to investigate further why the pure fixed setting turns out to be quite effective in comparison to the choice setting it is interesting to consider results from a pooled regression analysis given in Table 3. The dummy variable Choice indicates that the respective observation is taken from the choice setting. The interaction term Wage_Choice measures the potential difference in the effect of the wage on effort between both settings. The influence of the piece rate on effort is again captured by the variable PieceRate.

Table 3: Tobit-Regressions with effort as dependent variable (1. part)

\begin{tabular}{lccc}
\hline \hline & 1 & 2 & 3 \\
\cline { 2 - 4 } Wage & $0.571^{* * *}$ & $0.570^{* * *}$ & $0.467 * * *$ \\
& $(0.036)$ & $(0.036)$ & $(0.027)$ \\
Wage_Choice & $-0.191^{* * *}$ & $-0.184 * *$ & $-0.143^{* * *}$ \\
& $(0.064)$ & $(0.061)$ & $(0.036)$ \\
Choice & 0.269 & 0.174 & \\
& $(0.962)$ & $(0.941)$ & $0.082 * * *$ \\
PieceRate & $0.109^{* * *}$ & $0.110^{* * *}$ & $(0.011)$ \\
& $(0.031)$ & $(0.031)$ & \\
LastPeriod & $-3.919 * * *$ & & Yes \\
Constant & $(0.978)$ & & Yes \\
Period Dummies & $(0.766$ & & \\
\cline { 2 - 4 } Fixed effects & No & Yes & \\
(Groups) & No & No & \\
\hline \hline
\end{tabular}

Data pooled over both 1. parts. Standard errors are given in parentheses.

In regression 1 and 2 these are robust standard errors.

$*$ significant at $10 \% ; * *$ significant at $5 \% ; * * *$ significant at $1 \%$

The key point behind hypothesis 3 can be illustrated by considering the regression results with respect to Wage and the interaction term Wage_Choice. Note that increasing the wage by one unit increases the effort level by 0.571 in the pure fixed setting, and this effect is by one third significantly larger than in the choice setting. Furthermore this difference in the reaction to a change in the base wage made the latter a useful instrument to provide incentives in the pure fixed wage treatment. Raising the base wage by one unit here yielded an average return of 
1.142 units. These observations are well in line with our framing considerations: In the pure fixed setting agent's seem to focus on reciprocal behavior to assure future cooperation by the principal. Hence, they seem to put a stronger focus on the wage received in the current period than the agents in the choice setting, when they determine their effort levels. In contrast, the actual bonus payment offered plays an important role for the agent's effort selection in the choice setting and this seems to divert attention from the fixed wage.

Further support for the conjecture that the perception of the situation by the agents differs between the two settings can be given by an analysis of a questionnaire the participants had to fill out in the end of the experiment: agents qualitatively give rather different reasons for their effort choice in the two settings. Representative statements in the pure fixed setting are:

- "Type A player should earn almost - or even the same - amount as I do."

- "My partner should roughly make a similar profit as I do."

- "The other player and I should approximately yield the same number of points."

- "He should also earn (a little) money."

- "I wanted to keep him in a good mood."

It becomes quite clear from these answers that agents seem to take care of the principals' interests in the pure fixed setting. They apparently are concerned not to disappoint the other player - for instance because they hope for high wages in the future. The perception of the situation seems to be different in the choice setting. Here representative statements are:

- "Maximal profit for me"

- "Depending on the percentage offered"

- "I aimed at profit maximization."

- "Depending on the percentage share that player A gave me."

These answers suggest that the primary focus of the agents in the choice setting lies in (shortterm) profit maximization without paying noteworthy attention to the interests of the other player. In fact in the pure fixed setting agents mention the well-being of the principals significantly more often as a reason for their effort choice than agents do in the choice setting (Fisher Test, $p=5 \%$, two-tailed). ${ }^{15}$ Hence, we obtain:

\footnotetext{
${ }^{15}$ We classified all answers into five categories "Principal's Profits", "Own Profits", "Size of the transfer", "Future cooperation", "Size of the Piece Rate". The classification was independently confirmed by another researcher. The complete list of answers is available from the authors upon request.
} 


\section{Experimental Observation 3 (Perception of the Situation):}

In the fixed wage setting the base wage has a significantly stronger impact on the agents' effort choices. Whereas raising the base wage is on average not beneficial in the choice setting it is worthwhile when only fixed wages can be paid. Furthermore, agents have a stronger concern for the principal's well being in the pure fixed wage setting.

But recall that in the second part of the experiment the same principal-agent pairs continued to play in a different setting. In the treatment where we started with pure fixed wages, we switched to the choice setting for another 20 periods and vice versa. This method allows a further test of the framing interpretation.

\subsection{Persistence of Cognitive Frames}

If framing is of no importance or if the results could be explained purely by the logic of infinitely repeated games, then we should observe a similar picture for the pure fixed and the choice setting in the two parts of the experiment as the actions should be driven by their economic and distributional consequences which are the same as the participants did not know in advance that there was a second part.

But here we observe a completely different picture than in the first part. Figure 4 shows the average efforts in the second parts of the experiment.

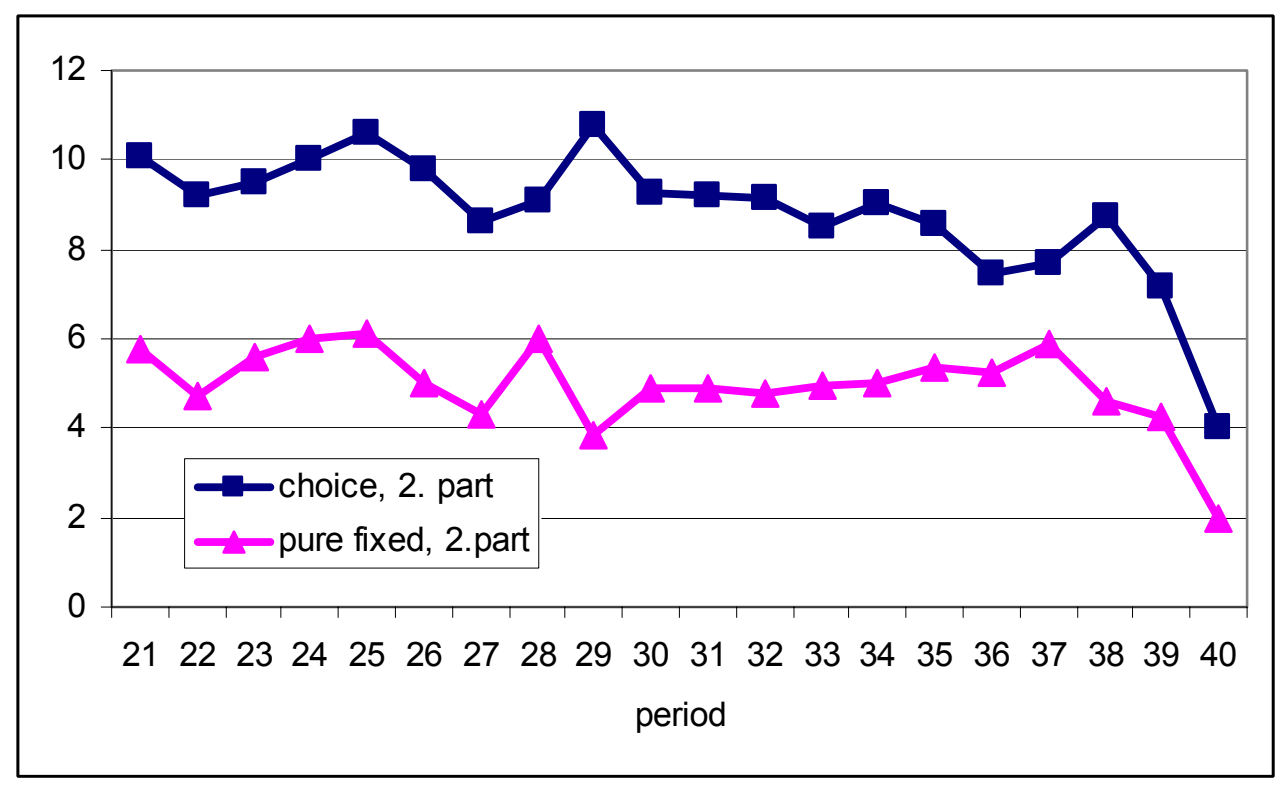

Figure 4: Average efforts in the 2. parts 
Note that quite surprisingly efforts are now higher in the choice setting than in the pure fixed setting. In the pure fixed setting the average is 4.96 , in the choice setting it is 8.83 . This difference is highly significant ( $p=0.4 \%$, Mann-Whitney $\mathrm{U}$ test, two-tailed). The same holds for the total profits of principals and agents: In the pure fixed setting the average total profits are 5.84 and in the choice setting they are significantly higher at $8.10(p=1.1 \%$, MannWhitney $U$ test, two-tailed). Average efforts and total profits of both parts are shown in Table 4 (second and fourth column).

Table 4: Overview of averages (both treatments and parts)

\begin{tabular}{lcccc}
\hline \hline & \multicolumn{2}{c}{ 1. treatment: pure fixed - choice } & \multicolumn{2}{c}{ 2. treatment: choice - pure fixed } \\
& pure fixed (1. part) & choice (2.part) & choice (1. part) & pure fixed (2. part) \\
\cline { 2 - 5 } Effort & 9.15 & 8.83 & 6.25 & 4.96 \\
Fixed wage & 15.32 & 12.96 & 7.41 & 8.17 \\
Piece rate & - & 7.55 & 21.02 & - \\
Percent. fixed wage & - & 0.69 & 0.49 & - \\
Total wage & 15.32 & 13.75 & 9.10 & 8.17 \\
Profit agents & 4.71 & 5.61 & 5.33 & 4.09 \\
Profit principals & 2.98 & 2.49 & 0.69 & 1.75 \\
Total profits & 7.69 & 8.10 & 6.02 & 5.84 \\
\hline \hline
\end{tabular}

Hence, the previous experience with an incentive scheme indeed strongly affected the wages and efforts chosen. To examine these effects in more detail it is interesting to consider the regression results regarding the effort determinants with pooled data from the second parts of both treatments given in Table 5 . 
Table 5: Tobit-Regressions with effort as dependent variable (2. parts)

\begin{tabular}{lccc}
\hline \hline & 1 & 2 & 3 \\
\cline { 2 - 4 } Wage & $0.494^{* * *}$ & $0.493^{* * *}$ & $0.381^{* * *}$ \\
& $(0.048)$ & $(0.047)$ & $(0.022)$ \\
Wage_Choice & 0.048 & 0.050 & $0.092^{* * *}$ \\
& $(0.066)$ & $(0.065)$ & $(0.033)$ \\
Choice & 0.362 & 0.334 & \\
& $(0.881)$ & $(0.873)$ & $0.107^{* * *}$ \\
PieceRate & $0.105^{* * *}$ & $0.105^{* * *}$ & $(0.012)$ \\
& $(0.012)$ & $(0.013)$ & \\
LastPeriod & $-3.650^{* * *}$ & & Yes \\
Constant & $(0.882)$ & & Yes \\
Period Dummies & 0.683 & & \\
\cline { 2 - 4 } Fixed effects & $(0.481)$ & Yes & \\
(Groups) & No & No & \\
\hline \hline
\end{tabular}

Data pooled over both 2. parts. Standard errors are given in parentheses. In regression 1 and 2 these are robust standard errors.

$*$ significant at $10 \% ; * *$ significant at $5 \% ; * * *$ significant at $1 \%$

Here we do not observe that the wage has a weaker effect in the choice setting as we did in the first part. But in contrast, in the second part fixed wages seem to have an (although weakly) larger impact within the choice setting as the coefficient of the interaction variable Wage_Choice is positive. Quite interestingly, similar to the findings from the first part of the experiment, the bonus payments have again a similar impact as predicted in the agency model: The coefficient of the variable PieceRate is again very close $(0.105)$ to the theoretical prediction of 0.12 .

It is interesting to compare the average effort in the pure fixed setting in the first part (when the participants started with this setting) with the efforts in the pure fixed setting in the second part (when they already have experienced the choice setting). As the graphs in Figures 1 and 4 already indicate, pure fixed wages lead to significantly higher efforts when principals and agents started with this pure fixed setting ( $p=0.9 \%$, Mann-Whitney $\mathrm{U}$ test, two-tailed). Again, the same relation holds for the total profits: Whereas total profits are on average 7.69 when the experiment starts with a pure fixed wage, they are only 5.84 after a preceding choice setting ( $p=3.6 \%$, Mann-Whitney U Test, two-tailed). Therefore, the prior experience of the choice setting seems to make it harder to establish a cooperative frame.

On the other hand, the choice setting yields significantly higher efforts and total profits when it follows after the pure fixed setting, than when it starts right from the beginning ( $p=2.1 \%$ for the efforts, $p=0.2 \%$ for the total profits, both Mann-Whitney U Test, two-tailed). 


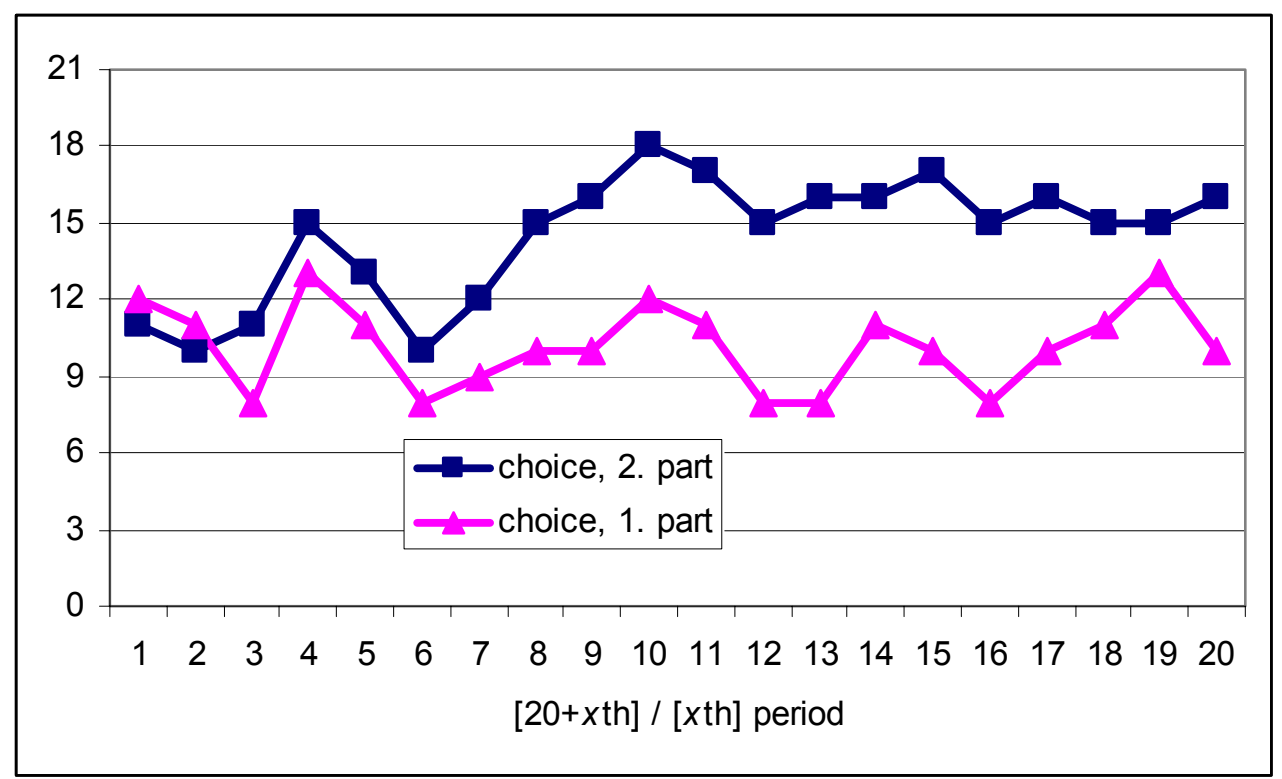

Figure 5: Time series of the average number of fixed wages in the choice settings ${ }^{16}$

The interesting question is therefore why the choice setting performed so well after the pure fixed wage setting. In this respect it is instructive to consider the numbers of fixed wages set within the choice setting in the second part. These numbers are plotted in Figure 5. Note, that when the choice option is introduced right from the beginning, quite constantly in about half of the cases the fixed wage is used over all rounds. But contrary to the choice setting in the first part, in the second part the principals switch back to fixed wages up to more than 75 percent of the cases.

Hence, principals learn that pure fixed wages work quite well in the first part of the experiment and experience in the second part that using the (costly) option to set a piece rate does not improve on this. The cooperative frame established in the first part of the experiment continues to be relevant for principals' and agents' actions. Pooled regressions with the two choice settings indeed confirm that the effect of the fixed wage on effort is significantly larger when subjects experienced a pure fixed setting before. ${ }^{17}$

Finally note, that a further reason for the lower effort levels are the lower fixed wages paid in the choice setting in the second part of the experiment: Wages are significantly higher in the first part (15.32) than in the second one (8.17) as can be seen from Table 5 ( $p=1,9 \%$, Mann-

\footnotetext{
16 Note that the time series starts with period 21 in the second part. Therefore, the abscissa should be read as indicating the period index within one part.

${ }^{17}$ These are reported in Table A2 in the appendix. See the interaction variable Wage_Part2.
} 
Whitney U test, two-tailed). Hence, principals are very cautious with the use of fixed wages to motivate agents after they experienced the choice setting. There is some indication that they may have performed better by paying higher wages: a pooled regression (see Table A1 in the appendix; see interaction variable Wage_Part1) shows that the effects of wages on effort levels are only weakly smaller after the prior experience with the choice setting. Hence, in part the reduced welfare is also due to the principals' altered perception of the situation as they are reluctant to offer high fixed wages after their experience with piece rates.

We can again summarize:

\section{Experimental Observation 4 (Persistent Effects on Cognitive Frames):}

Effort levels and profits are significantly higher in the choice setting when the participants previously have experienced the pure fixed wage setting. Conversely effort levels and profits are significantly lower in the pure fixed wage setting when the participants have experienced the possibility of using piece rates before.

These observations therefore confirm hypothesis 4: We indeed find evidence that the perception of the economic situation of principal and agent is persistently affected by the form of the incentive scheme. Agents who have experienced performance pay in the past are less reciprocal. The previous experience of a pure fixed wage setting leads to more cooperative behavior. Furthermore note that these observations are hard to understand by the repeated game logic laid out in 3.2. According to this logic effort levels should decrease in the second part when piece rates become feasible as sanctioning the agent by offering zero wages is no longer a credible threat. Similarly, effort levels should increase when piece rates are no longer feasible. Hence, we can clearly reject hypothesis 5 .

\section{Summary}

In this paper we experimentally investigate the effectiveness of two different reward schemes: fixed and a combination of fixed and variable wages. We report two treatments, each consisting of two parts. In part one of the first treatment the principal may repeatedly propose a fixed wage to the agent. After each wage transfer the agent chooses an effort level, where exerting effort is costly for the agent. In part one of the second treatment the principal may choose between a fixed wage or a combination of fixed and variable pay, which again is always followed by an agent's effort choice. The second parts of both treatments consist of the same setting as the respective first parts of the other treatment. 
Interestingly, in the so called choice setting where principals had the possibility to introduce incentive schemes in the first part of the experiment the results come astonishingly close to the equilibrium prediction of a simple agency model. However, we also observe a crowding out effect if the first parts of our two treatments are compared as efforts are lower in the case where piece rates can be paid. Giving the principal the additional possibility to set up an incentive scheme instead of a pure fixed wage regime leads to lower profits by the principal as well as a welfare loss.

However, the later introduction of the possibility to pay a piece rate in the second part does not crowd out incentives once the participants have experienced that pure fixed wage can work quite well. Principals continue to offer fixed wages although they have the opportunity to propose variable pay.

When being confronted with the possibility of incentive schemes right from the beginning lower average efforts are attained compared to a situation where principals and agents have experienced pure fixed wages before. Furthermore, the prior experience of variable pay reduces the willingness to exert effort by the agents and the willingness to pay high wages by the principals when only fixed wages can be offered. Average effort and overall efficiency is significantly higher under purely fixed wages if agents have not experienced variable pay before.

To sum up, our result yield clear indications that the past experience with compensation systems has an important effect on mental frames under which individuals act and those effects may be persistent over time. From a practical perspective this indicates that the use of incentive schemes should be carefully considered, as switching to fixed wages once piece rates have been experienced may lead to worse results as compared to a situation when they have never been introduced.

\section{References}

Anderhub, Vital, Gächter, Simon, and Königstein, Manfred (2002) "Efficient Contracting and Fair Play in a Simple Principle-Agent Experiment”, Experimental Economics 5, 5-27.

Baker, George, Gibbons, Robert and Murphy, Kevin J. (1994) "Subjective Performance Measures in Optimal Incentive Contracts", Quarterly Journal of Economics, 1125-56.

Bohnet, Iris, Frey, Bruno, S. Huck, Steffen (2001) "More Order with Less Law: On Contract Enforcement, Trust, and Crowding", American Political Science Review 95(1), 131-144.

Bohnet, Iris, Huck, Steffen (2004) "Repetition and Reputation: Implications for Trust and Trustworthiness When Institutions Change", American Economic Review 94(2), 362-366.

Bolton, Gary and Ockenfels, Axel (2000) "ERC - A Theory of Equity, Reciprocity and Competition", American Economic Review, 90, 166-193. 
Bowles, Samuel (2005) "Social Preferences and Public Policy: Are good laws a substitute for good citizens?", Santa Fe Institute Working Paper.

Brandts, Jordi and Charness, Gary (2004) "Do Labour Market Conditions Affect Gift Exchange? Some Experimental Evidence”, Economic Journal 114, 684-708.

Bull, Clive, Schotter, Andrew, Weigelt, Keith (1987) “Tournaments and Piece Rates: An Experimental Study", Journal of Political Economy 95, 1-33.

Cameron, Judy., Pierce, W. David (1994) "Reinforcement, Reward, and Intrinsic Motivation: A Meta Analysis", Review of Educational Research 64, 363-423.

Charness, Gary (2004) “Attribution and Reciprocity in an Experimental Labor Market", Journal of Labor Economics 22(3), 665-688.

Charness, Gary and Dufwenberg, Martin (2004) "Promises and Partnerships", Discussion Paper, University of California at Santa Barbara.

Charness, G. and Rabin, M. (2002) “Understanding Social Preferences with Simple Tests” Quarterly Journal of Economics, 117, 817-869.

Deci, Edward L. (1971) "Effects of Externally Mediated Rewards on Intrinsic Motivation," Journal of Personality and Social Psychology 18, 105-115.

Deci, Edward L., Koestner, R., Ryan, Richard M. (1999) “A meta-analytic review of experiments examining the effects of extrinsic rewards on intrinsic motivation”, Psychological Bulletin, 125, 627-668.

Eisenberger, R., Cameron, Judy (1996) "Detrimental effects of reward: Reality of myth?" American Psychologist 51, 1153-1166.

Falk, Armin and Kosfeld, Michael (2004) “Distrust - The Hidden Cost of Control”, IZA Discussion Paper 1203.

Fehr, Ernst, Kirchsteiger, Georg, Riedl, Arno (1993) "Does Fairness prevent Market Clearing? An Experimental Investigation", Quarterly Journal of Economics 108 (2), 437-460.

Fehr, Ernst, Gächter, Simon, Kirchsteiger, Georg (1997) "Reciprocity as a Contract Enforcement Device: Experimental Evidence”, Econometrica 65(4), 833-860.

Fehr, Ernst and Gächter, Simon (2002) “Do Incentive Contracts Undermine Voluntary Cooperation?", University of Zurich Discussion Paper.

Fehr, Ernst and Falk, Armin (2002) "Psychological Foundations of Incentives", European Economic Review 46, $687-724$

Fehr, Ernst and Rockenbach, Bettina (2003) “'Detrimental Effects of Sanctions on Human Altruism', Nature 422, 137-140.

Fehr, Ernst, Klein, Alexander, Schmidt, Klaus (2004) “Contracts, Fairness, and Incentives”, CESifo Working Paper No. 1215, Munich.

Fehr, Ernst, and List, John A. (2004) "The Hidden Costs and Returns of Incentives - Trust and Trustworthiness among CEOs", Journal of the European Economic Association 2(5), 743-771.

Fehr, Ernst, Schmidt, Klaus (1999). “A Theory of Fairness, Competition, and Cooperation”, Quarterly Journal of Economics 114, 817-868.

Fischbacher, Urs (1999) “Z-Tree: A Toolbox for Readymade Economic Experiments” University of Zurich.

Freeman, Richard B., Kleiner, Morris M. (2005) "The Last American Shoe Manufacturers: Decreasing Productivity and Increasing Profits in the Shift from Piece Rates to Continuous Flow Production", Industrial Relations 44(2), 307-330.

Frey, Bruno S. (1997) "Not Just For the Money - An Economic Theory of Personal Motivation”, Edward Elgar Publishing.

Frey, Bruno S. and Oberholzer-Gee, Felix (1997) "The Cost of Price Incentives: An Empirical Analysis of Motivation Crowding-out”, American Economic Review 87, 746-755.

Frey, Bruno S. and Jegen, Reto (2001) “Motivation Crowding Theory”, Journal of Economic Surveys 15 (5), 589-611. 
Gächter, Simon, Königstein, Manfred, Kessler, Esther (2005) "Performance Incentives and the Dynamics of Voluntary Cooperation, Discussion Paper University of Nottingham.

Gibbons, Robert (1998) “Incentives in Organizations”, Journal of Economic Perspectives 12(4), 115-132.

Gneezy, Uri (2005) “The W effect of incentives”, Discussion paper, University of Chicago.

Gneezy, Uri, Rustichini, Aldo (2000a) "Pay Enough or Don't Pay at All”, Quarterly Journal of Economics 115 (3), 791-810.

Gneezy, Uri, Rustichini, Aldo (2000b) “A Fine is a Price”, Journal of Legal Studies 29, 1-17.

Kohn, Alfie (1993) “Why Incentive Plans Cannot Work”, Harvard Business Review, 54-63.

Lazear, Edward P. (1999) "Personnel Economics: Past Lessons and Future Directions", Journal of Labor Economics 17(2), 199-236.

Lazear, Edward P. (2000) “Performance Pay and Productivity”, American Economic Review 90(5), 1346-1361.

Lepper, Mark, R., Greene, David, Nisbett, R. E. (1973) "Undermining children's intrinsic interest with extrinsic rewards: A test of the "overjustification" hypothesis", Journal of Personality and Social Psychology 28, 129-37.

Levine, David (1998) "Modeling Altruism and Spitefulness in Experiments", Review of Economic Dynamics, 1, 593-622.

Manthei, Kathrin (2004) "Pay - But Don't Pay Too Much: An Experimental Study on the Impact of Incentives", Discussion Paper University of Cologne. http://ssrn.com/abstract=614742.

March, James G. (1994) “Primer on Decision Making - How Decisions Happen”, The Free Press, New York.

Nalbantian, Haig R., Schotter, Andrew (1997) "Productivity Under Group Incentives: An Experimental Study", American Economic Review 87, 314-341.

Paarsch, Harry J., Shearer, Bruce (1999) "The Response of Worker Effort to Piece Rates - Evidence from the British Columbia Tree-Planting Industry”, Journal of Human Resources 34, 643-667.

Paarsch, Harry J., Shearer, Bruce (2000) "Piece Rates, Fixed Wages, and Incentive Effects: Statistical Evidence from Payroll Records”, International Economic Review 41(1), 59-92.

Pittmann, Thane S., Heller, Jack F. (1987) “Social Motivation”, Annual Review of Psychology 38, 461-89.

Prendergast, Canice (1999) “The Provision of Incentives in Firms”, Journal of Economic Literature 37(1), 7-63.

Schelling, Thomas C. (1980) “The Strategy of Conflict”, Harvard University Press.

Schmidt, Klaus and Schnitzer, Monika (1995) "The Interaction of Explicit and Implicit Contracts", Economics Letters, 48, 193-199.

Selten, Reinhard and Stoecker, Rolf (1986) "End Behavior in Sequences of Finite Prisoner's Dilemma Supergames", Journal of Economic Behavior and Organization 7, 47-70.

Shearer, Bruce (2004) "Piece Rates, Fixed Wages and Incentives: Evidence from a Field Experiment”, Review of Economic Studies 71, 513-534.

Sugden, Robert (1989) “Spontaneous Order”, Journal of Economic Perspectives 3(4), 85-97.

Tang, Shu Hua, Hall, Vernon C. (1995) "The overjustification effect: A meta-analysis", Applied Cognitive Psychology 9, 365-404.

Tenbrunsel, Ann E., Messick, David M. (1999) "Sanctioning Systems, Decision Frames, and Cooperation”, Administrative Science Quarterly 44, 684-707.

Tversky, Amos and Kahneman, Daniel (1981) "The Framing of Decisions and the Psychology of Choice", Science 211, 453-458.

Tversky, Amos and Kahneman, Daniel (1986) "Rational Choice and the Framing of Decisions", Journal of Business 59(4), 251-278.

Van Huyck, John B., Battalio, Raymond C. and Beil, Richard O. (1991): "Strategic Uncertainty, Equilibrium Selection, and Coordination Failure in Average Opinion Games", Quarterly Journal of Economics, 885-910.

Wiersma, Uco J. (1992) "The effects of extrinsic rewards in intrinsic motivation: A meta-analysis", Journal of Occupational and Organizational Psychology 65, 101-114. 


\section{Appendix:}

\section{Further regression results}

Table A1: Tobit-Regressions with effort as dependent variable (pooled fixed settings)

\begin{tabular}{lccc}
\hline \hline & 1 & 2 & 3 \\
\cline { 2 - 4 } Wage & $0.498^{* * *}$ & $0.497 * * *$ & $0.382 * * *$ \\
& $(0.049)$ & $(0.048)$ & $(0.023)$ \\
Wage_Part1 & 0.055 & 0.053 & $0.071 * *$ \\
& $(0.063)$ & $(0.062)$ & $(0.033)$ \\
Part1 & 0.404 & 0.433 & \\
& $(0.827)$ & $(0.814)$ & \\
LastPeriod & $-4.246^{* * *}$ & & \\
& $(0.989)$ & & Yes \\
Constant & 0.633 & & Yes \\
\cline { 2 - 4 } Period Dummies & $(0.503)$ & Yes & \\
Fixed effects & No & No & \\
(Groups) & No & & \\
\hline
\end{tabular}

Data pooled over both pure fixed settings.

Robust standard errors are given in parentheses.

* significant at $10 \%$; $*$ significant at $5 \% ; * * *$ significant at $1 \%$

Table A2: Tobit-Regressions with effort as dependent variable (pooled choice settings)

\begin{tabular}{lccc}
\hline \hline & 1 & 2 & 3 \\
\cline { 2 - 4 } Wage & $0.378^{* * *}$ & $0.388^{* * *}$ & $0.330^{* * *}$ \\
& $(0.051)$ & $(0.046)$ & $(0.023)$ \\
Wage_Part2 & $0.181^{* * *}$ & $0.171^{* * *}$ & $0.146^{* * *}$ \\
& $(0.067)$ & $(0.064)$ & $(0.035)$ \\
Part2 & -0.348 & -0.268 & \\
& $(1.024)$ & $(0.999)$ & $0.081^{* * *}$ \\
PieceRate & $0.108^{* * *}$ & $0.110^{* * *}$ & $(0.010)$ \\
& $(0.030)$ & $(0.030)$ & $0.035^{* *}$ \\
PieceRate_Part2 & 0.001 & 0.005 & $(0.017)$ \\
& $(0.031)$ & $(0.030)$ & \\
LastPeriod & $-3.430^{* * *}$ & & Yes \\
Constant & $(0.884)$ & & Yes \\
Period Dummies & 1.066 & & \\
Fixed effects & $(0.688)$ & Yes & \\
(Groups) & No & No & \\
\hline \hline
\end{tabular}

Data pooled over both choice settings.

Robust standard errors are given in parentheses.

$*$ significant at $10 \% ; * *$ significant at $5 \%$;** significant at $1 \%$ 
Table A3: Tobit-Regressions with effort as dependent variable (pure fixed wage - choice)

\begin{tabular}{lccc}
\hline \hline & 1 & 2 & 3 \\
\cline { 2 - 4 } Wage & $0.553^{* * *}$ & $0.551^{* * *}$ & $0.525^{* * *}$ \\
& $(0.034)$ & $(0.016)$ & $(0.018)$ \\
Wage_Choice & -0.006 & -0.004 & -0.033 \\
& $(0.025)$ & $(0.024)$ & $(0.025)$ \\
Choice & -0.069 & -0.096 & 0.303 \\
& $(0.508)$ & $(0.429)$ & $(0.436)$ \\
PieceRate & $0.106^{* * *}$ & $0.105^{* * *}$ & $0.104 * *$ \\
& $(0.013)$ & $(0.012)$ & $(0.012)$ \\
LastPeriod & $-3.913 * * *$ & & \\
& $(0.967)$ & & Yes \\
Constant & 1.020 & & Yes \\
Period Dummies & $(0.627)$ & Yes & \\
Fixed effects & No & No & \\
(Groups) & & & \\
\hline \hline
\end{tabular}

Data pooled over both parts of the 1. treatment.

Standard errors are given in parentheses.

In regression these are robust standard errors.

$*$ significant at $10 \% ; * *$ significant at $5 \% ; * * *$ significant at $1 \%$

Table A4: Tobit-Regressions with effort as dependent variable (choice-pure fixed wage)

\begin{tabular}{lccc}
\hline \hline & 1 & 2 & 3 \\
\cline { 2 - 4 } Wage & $0.506^{* * *}$ & $0.506^{* * *}$ & $0.464^{* * *}$ \\
& $(0.050)$ & $(0.021)$ & $(0.022)$ \\
Wage_Choice & $-0.128^{* *}$ & $-0.122^{* * *}$ & $-0.126^{* * *}$ \\
& $(0.052)$ & $(0.030)$ & $(0.029)$ \\
Choice & 0.600 & 0.543 & $0.836^{* *}$ \\
& $(0.784)$ & $(0.421)$ & $(0.402)$ \\
PieceRate & $0.108^{* * *}$ & $0.109^{* * *}$ & $0.095^{* * *}$ \\
& $(0.030)$ & $(0.008)$ & $(0.008)$ \\
LastPeriod & $-3.757 * * *$ & & \\
Constant & $(0.990)$ & & \\
& 0.482 & & Yes \\
Period Dummies & $(0.511)$ & Yes & Yes \\
\cline { 2 - 4 } Fixed & No & & \\
(Groups) & No & & \\
\hline \hline
\end{tabular}

Data pooled over both parts of the 2. treatment.

Standard errors are given in parentheses.

In regression these are robust standard errors.

$*$ significant at $10 \% ; * *$ significant at $5 \% ; * * *$ significant at $1 \%$ 


\section{Appendix:}

\section{Experimental I nstructions}

(In the following we give an example instruction from the treatment PURE FIXED in part one and CHOICE in part two. Original instructions were in German; they are available upon request from the authors.)

\section{I nitial capital and groups}

- At the beginning of the experiment each participant is endowed with a certain amount of money (initial capital) in the experimental currency "Talers".

- The experiment consists of two parts.

\section{Part One}

\section{Rounds, Groups, and Roles}

- The first part consists of $\mathbf{2 0}$ rounds.

- During the first part of the experiment you belong to a group of two participants, yourself included. You do not know the identity of the other member of your group. The groups do not change throughout part one.

- There are two different roles in each group: a type-A player and a type B-player. The roles are assigned randomly in the beginning and they do not change either throughout part one.

\section{Sequence of one Round}

\section{- Transfer by type-A player}

At the beginning of each round, the type-A player announces a transfer in the experiment's currency "Talers" to the type-B player. He specifies an amount out of the set $\{0, \ldots, 40\}$. This transfer is implemented immediately. The determined amount is taken from the type A-player and credited to the type-B player.

\section{- Selection of a number by the type-B player}

When the transfer has taken place, the player of type $B$ has to select a number out of the integer set $\{0, \ldots, 25\}$. The higher the number chosen, the higher are the costs the type B-player has to bear (see cost table). After the selection the respective costs are subtracted (in "Talers") from the account of the type B-player.

The so-called result is twice the selected number. This result is announced to the type-A player and credited onto his (type-A's) account. The round ends with the announcement of the result and a new one will be started. 


\section{I nitial Capital and Total Payoffs}

- At the end of the experiment, the total account will be changed into $€$ at an exchange rate of $6 €$ per 100 Talers and will be paid in cash to the player.

\section{Please note:}

- During the experiment no communication is permitted - except via the experimental software.

- All decisions are made anonymously, i.e. no one gets to know the identity of someone else who has made a certain decision.

- In addition the final payment is made anonymously, i.e. nobody learns, how much another participant has earned.

\section{Part Two}

\section{Rounds, Groups, and Roles}

- Part two of the experiment also consists of $\mathbf{2 0}$ rounds.

- You belong to the same group as in part one of the experiment

- Your role is also the same as in part one of the experiment

\section{Sequence of one Round}

\section{- Selection of the transfer by the type-A player}

At the beginning of each period the type-A player can decide whether he wants to transfer a purely fixed amount to the type-B player or whether he wants to transfer an amount which is dependent on the result. If she opts for an amount dependent on the result, this costs her 2 "Talers", which are subtracted from her account immediately.

\section{- Specification of the transfer by the type-A player}

After having selected the transfer the type-A player has to specify it.

If he opted to transfer a fixed amount he specifies an amount of the experiment's currency "Talers" out of the set $\{0, \ldots, 40\}$. This transfer is implemented immediately. The determined amount is taken from the type A-player and credited to the type B-player.

If he opted to transfer an amount which is dependent on the result, then he has do two things. At first he specifies a fixed basic amount of the experimental currency "Talers" out of the set $\{0, \ldots, 40\}$. Secondly he determines a percentage at which the type-B player participates in the result. He can select a share out of the set $\{10 \%, 20 \%, 30 \%, \ldots, 100 \%\}$. The fixed basic amount is taken from the type A-player and credited to the type B-player immediately. As soon as the result is realized (see below), the type-B player receives the specified percentage of the result and the type-A player receives the remainder of the result. 


\section{- Selection of a number by the type-B player}

After the type-A player has selected and specified a transfer the type-B player will be informed about the kind of transfer (fixed or dependent on the result). Then the type-B player selects a number out of the integer set $\{0, \ldots, 20\}$. The higher the number chosen, the higher the costs the type B-player has to bear (see cost table). After the selection the respective costs are subtracted (in "Talers") from the account of the type B-player. The so-called result is twice the selected number. If a fixed transfer was chosen this result is announced to the type A-player and credited onto his (type A's) account. If this transfer is dependent on the result, the type- $B$ player is credited the percentage of the result, which had been specified by the type-A player earlier. The type-A player receives, the remainder of the result. The round ends with the announcement of the result and a new one will be started. 


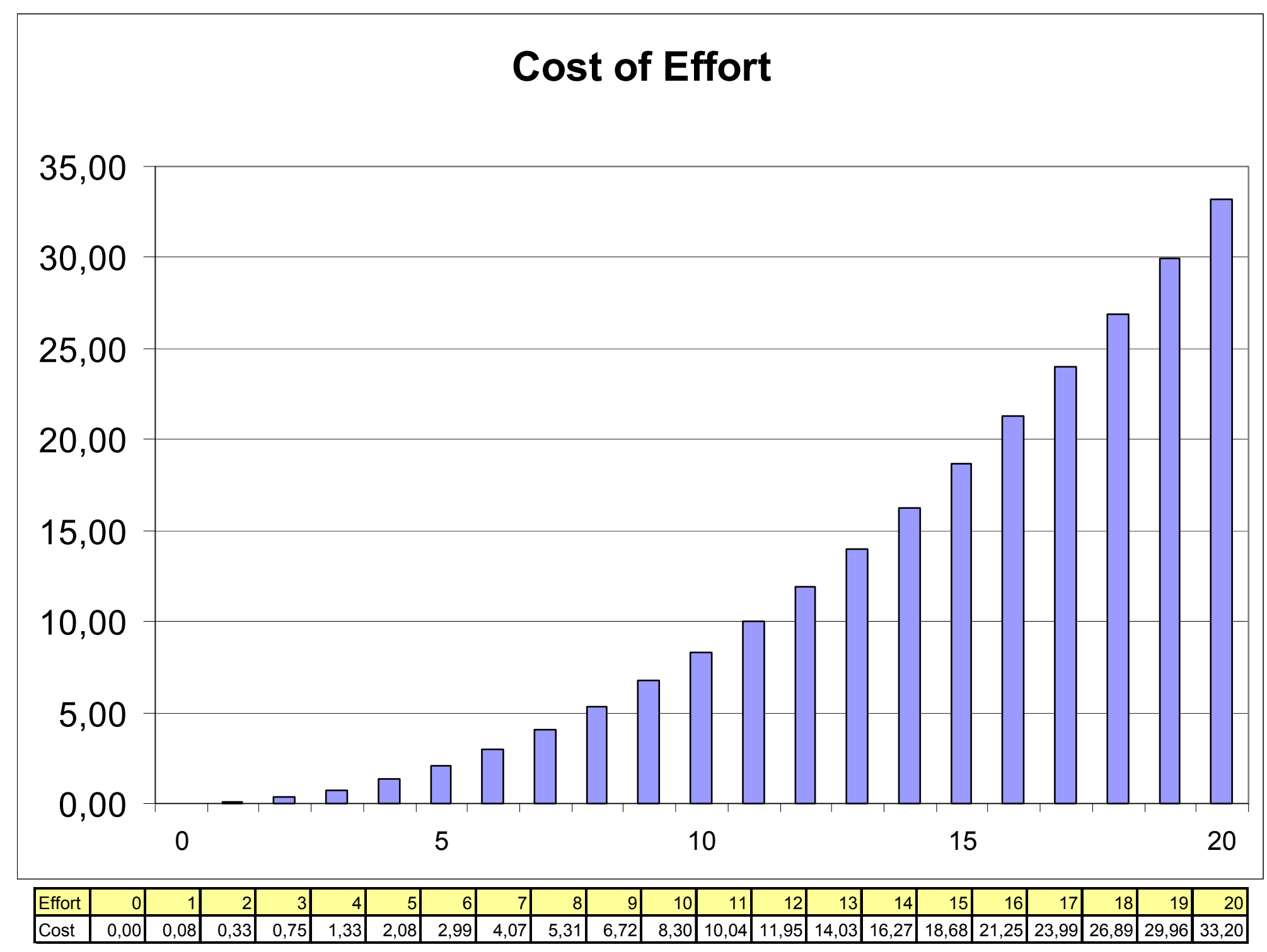

